pound radicles are nearly always multiples of one another, and their magnitude is sufficient to establish the complexity of the radicles themselves.

The combinations of the same order formed by the simple radicles have all of them nearly the same atomic heat, as the observations of Naumann and Regnault have shown. On the contrary, combinations of the same order formed by a series of analogous compound radicles exhibit specific heats which tend to increase proportionally with the variation of their atomic weights. This, which is precisely the opposite of the relations which would have been supposed to exist between compounds of the same order at the time of Naumann's researches on the identity of the specific atomic weights of the carbonates and sulphates, is another proof of the complexity of these radicles.

To sum up, the study of the specific heats established by the most recent researches, tends to prove that there is a positive characteristic which, it seems to me, distinguishes the elements of modern chemistry from its compounds, and shows that no known compound body ought to be considered as of the same order as an actually simple one. The importance of such a characteristic cannot be doubted, and it becomes greater on account of the mechanical meaning which modern theories ascribe to specific heat. This I feel bound to put in evidence.

Nevertheless, and I ask permission to return once more to this point, exaggerated conclusions must not be drawn from such an opposition between the mechanical and physical characteristics of our simple and compound bodies.

If our elements have not as yet been decomposed and appear not to be decomposable by the forces which are at present at the command of the chemist, and which, as M. Dumas at the time of his discussion with Despretz justly remarked, have been so often tried in vain, nothing compels us to assert that they are not decomposable in another way than our compounds are; as, for instance, as Mr. Lockyer asserts, by means of the forces acting in cosmical space. Nor does anything prevent the supposition that such a discovery as that of voltaic electricity would enable the chemists of the future to overpass the limits which are imposed upon us.

The possible fundamental identity of the matter constituting our elements, and the possibility of transmuting into one another the so-called elements, can moreover be admitted into the category of more or less plausible hypotheses without it necessarily resulting that there is a single really existing matter of which our actual elements represent mequal states of condensation. In fact nothing compels us to conceive the existence of a final decomposition which shall tend necessarily to reduce our elements either to more simple bodies, from the addition of which they arise, or to multiples of a single elementary ponderable unit. The various states of equilibrium under which the fundamental matter manifests itself would exhibit certain general relations to each other analogous to those which exist between the multiple values of the same function. According to this hypothesis, an e!ementary body could be, broken up without being destroyed in the ordinary meaning of that word. At the moment of its destruction it would suddenly change into one or more simple bodies identical with, or analogous to, our elements. But the atomic weights of the new elements would not show any simple relation to the atomic weight of the element which had by its metamorphosis produced then, the absolute weight alone would remain unaltered throughout the catena of changes.

But I do not wish to insist further on this hypothesis of a matter fundamentally identical, although multiform in its appearances, and characterised in each one of them by a peculiar mode of motion, such, in fact, that no single one of them can be definitely considered as the starting-point of all the others. Nevertheless, we shall only be too glad if Mr. Lockyer, guided by stellar spectral analysis, succeeds in shedding a new light upon these bypotheses, and continues to investisale questions which M. Dumas raised forty years ago in a book which has contributed so much to our scientific education.

i. J. F.

\section{SCIENCE IN LIEGE}

WE have received a somewhat bulky volumie of Memoirs of the Royal Society of Science in Liege (1873), in which a considerable variety of subjects comes under notice ; zoology and mathematics being, periaps, the most largely represented.

An éloge, by Prof. Morren, on Jean Théodore Lacordaire (who died in 1870 ), is accompanied with a good portrait of that emi- nent naturalist. Lacordaire was originally destined for the law, which, however, he left for commerce. Going out to South America in a business capacity, his bias for natural research was quickly developed, and he commenced those labours to which his after life was devoted. In I 835 he became professor of zoology at Liege, where he continued till his death. Lacordaire was a voluminous writer, but his stmmmum opus is the Genera des Co. léptères, which is remarkable for the minuteness of its details and its rigorous truthfulness.

For some years past we have heard a great deal about the ser. vices which birds render to agriculture by destroying injurious insects. The sentiment is widespread, and vigorous measures of bird protection have been taken in various countries of Europe. M. Edouard Perris here brings forward a somewhat opposite view, which he supports by many curious facts trom a long expe. rience of country life. Fis position is, briefly, the following :I. Birds are congregated in considerable numbers only in the migration time in autumn and spring, when insects are very much less numerous than in the fine season. The rest of the time they live in pairs, sparsely distributed, and rare in cultivated parts, while the insects come forth en masse to do their mis. chievous work. 2. Birds destroy insects largely, but these insects are, in great part, indifferent, others are eminently usefil ; and the really hurtful species destroyed are in very small proportion to the whole. Thus the birds do us little service; and they often do injury in destroying our carnivorous and parasitic insects, as well as attacking fruits and seeds. 3. The insects we have most to complain of are, some of them, big enough to brave the birds, others are too small to attract them; ofhers prove dis. agreeable as food; many are nocturnal in habits, or, by theix immobility, escape notice; some live underground, or in houses; and all have an astonishing fecundity which is quite bafling to human resources. 4. Larva and caterpillars, which do the most damage, live nearly all concealed under ground, under bark, in the deep parts of wood, in the roots of plants, in fruits, in in. habited places, \&c, and furnish little tribute to the birds. 'Those which develop in open air are generally provided with hairs which protect them; some are noctumal, some are extremely small. All these facts, in the author's opinion, should greatly modify the ordinary view as to the utility of birds in asriculture. He points out that certain natural infuences tend to preserve an equilibrium in the insect world; such are, famine occasioned by the too great multiplication of individuals, meteorological phenomena adverse to their growth or metamorphosis, and the abundant production of parasites. M. Perris cloes not find fault with measures of bird protection, but objects to the undue merit which is assigned to birds. He urges upon farmers the imiportance of exercising more discermment in their destructive measures, and of respecting many animals they often regard as nuisances, such as hedgehogs, snakes, lizards, toads, \&c.

Medical men will doubtless be interested in two teratological observations communicated by Dr. Eligene Charlier. One is that of a child inferiorly double, or a double ileadelphous monster. It is a kind of monstrosity of which Is. Geoffrey Saint-Hilaire supposed the existence, but of which he did not know any authentic case. The other monstrosity is a new variety of pygo. melian chicken; the animal has two accessory limbs joined to the normal wing and leg on one sioue. The forms are represented in plates annexed to the notes in question.

An important mathematical paper by M. Brasseur, fumishes

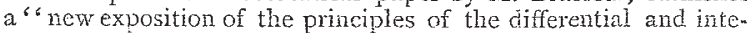
gral calculus." The following sentences from a commendatory preface by M. Folie, will give some idea ot the point of viev which the author adopt.s. "Of all the modes of considering the differential calculus, we do not know of any more philosophical than that of Newton ; but it requires, to be properiy understood, a mind well trained to metaphysical speculations. We have, indeed, known good analysts who never grasped it, though they had studied at the best sources. The great difficulty of the differential calculus is that it attempts to analyse the idea of continuity; it seeks to express how a function passes in a continuous manner from one state to another; and it is this passage which has given rise to the contradictory idea of the infinitely little, to the indirect idea of limits, and to the philosophic idea of Newton. Brassenr has avoided this great difficulty; he has succeeded in rendering the method of La Grange, who only employs finite analysis, as convenient in its applications, and as rigorous, as that of limits or of fluxions. We will even say that his method has, from the educational point of view, the advantage, over that of fluxions, of not requiring any metaphysical notion; and, over that 
of limits, of being much more direct, aird not exposed to any attack, e: en specious. Instead of amalysing the idea of continuity he studies two successive states of a continuous function; and cointinnity only comes in so far as that the difference between these two slates may become as small as we choose without ever becoming wil, as seems to be the case in limits; or infinitely little, in the old signification of the word, a signification simply absurd."

We simply name, in conclusion, the following zoological lists, which make up the greater part of the volume:-Monography of the Malabricles, by M. de Marseul ; Synopsis of the Scolytides, by $M$. Chapuis; and new or little known Araneides from the Sontiz of Europe, by M. Simon.

\section{SCIENTIFIC SERTAIS}

Zsitschrift jür Ethnologie (1873). The fifth number of the journal for last year is of less than average importance to English readers, since the principal article-a most valuable and comprehensive one on the descriptive ethnology of Bengal--is a translation of Colonel Dalton's digest of the official reports drawn up by the different Commissioners of the province, and published at the cost of the Indian Government. This work, which supplies information that can nowhere else be found in regard to the tribes occupying the Brahmaputra and Gangetic valieys, must henceforth be considered as indispensable to every student of Indian ethnology, and the editors of the Zeitschrift have done good service in making it known to their readers. In an article on a proposed improvernent in the methods of craniometry now in use, Dr. Jhering passes in review the difference in the values of the indices, proposed by Blumenbach, Retzins, Broca, and others, for the definition of Dolichocephalic and Brachycephalic types. His three main propositions are briefly these :- $x$. All cranial meastrements must be projected in a line that is parallel or vertical to the horizontal base of the cranium. 2. The most important maximum and minimum dimersions should be obtained per se, and without reference to distances from definite anatomical points. 3. For all parts not in the medial plane, the percentage of lengths and heights must be given at the points where such parts intersect these diameters. Dr. Thering thinks that it is time finally to set aside the theory transmitted from Blumenbach, and througin Retzius to the present day, that every race possesses at once a special language, and a special type of cranium. According to his view it is never possible to deterine with certainty from the form of the skill the precise race from which an individual has sprung, and in his opinion the problems which ought to engage the attention of future students of craniology are the determination of the mean cranial type of each race; and the definition of the limits within which each special type varies among different races. Finally the author wishes to show that craniology is not competent to determine questions of race, but is merely to be accepted as an auxiliary science to anthropology. The learned missionary, Th. Jellinghaus, to whom we are already indebted for many valuable contributions to our knowledge of the languages spoken by the outlying tribes of our vast empire in India, gives in this number a. short account of the language of the Munda Kohls of Chota Nagpore. The peculiarities of their tongue seem to be a distinct duat for all three persons : the formation of the plural and dual by the addition of an abbreviated form of the third personal pronoun; the insertion of the letter $p$ with the vocal accent for the formation of the plural and dual of certain nouns and adjectives; the interpellation of the letter $n$ in the root-syllable of the verb to form the abstract noun. The units of the Munda Kohls' numeral system are ro and $2 \mathrm{O}$. The author describes these people as kind and simple in their social relations with one another. Herr Virchow draws attention to a specimen of a synostolic cranium as the form has been figured and described by J. B. Davis in his work on "Sjynostolic Crania among Aboriginal Races of Man" (Elaarlem, I865). As this skull belonged to a rachitic child, and similar skulls, in which the calvaria was entirely obliterated, and the cranial bones were thickened ontwardly, are preserved in the Berlin and other Pathologico-Anatomical collections, and were taken from rachitic subjects, Herr Virchow considers that stuch forms must be held to be quite independent of ethnological peculiarities, and that their occurrence amongst savage or aboriginal races must be ascribed to the frequent presence amonst them of rachitisn- -i fact to which Pruner-Bey has already drawn attention. We canno close our notice of the con- tents of this number without mentioning an interesting communication by Dr. Brehm in regard to his experience-based on an eight years' acquaintance-of the habits of the Chimpanzee under confinement. The last individual which fell under his notice, and which died at the age of four from pulmonary disease, showed, in many respects, an aptitude of comprehension, a docility and a capability of practising the ordinary usages of daily life which made the animal an interesting and wholly unobjectionable inmate of Dr. Virchow's house, where he ran about with little more surveillance than would have been awarded to a human child of the same age. The result of the learned author's experience of this, and other individuals of the race is, that although not human, there is very much of the element of humanity in the Chimpanzee.

Poggendorff's Annalen der Physik und Chemic, No. 9, 1873. - This number commences with a theoretical examination, by the editor, of the action of Holtz's electrical machines of the "second" kind, those being meant which have two discs rotating in opposite directions, whereas in the "first," and more common kind, one disc rotates while the other is stationary. The author's view is, not that there is suction, by the conductors, of the electricities expanded in the insulators, as commonly supposed, but conversely, that electricities separated in the conductors, through induction, stream over to the insulators. In this way, both modes of excitation, by induction and by inflow (Einströmung), are explained on one principle. The same holds good for machines of the first kind.-M. Julius Thomsen contimues his "Thermo-chemical Researches," investigating here the action of four agents of reduction, and seven of oxidation. -Dr. Muiller describes a new tangent galvanometer and rheo. stat, free from the disadvantages of not being equally available for currents of all degrees of intensity, and of waste of time in use. The galvanometer differs from ordinary ones in the arrangements for reading and deadening; and, in the rheocord, to neutralise heating effects with strong currents, the wires are surrounded by distilled water. -There are four papers referring to the "horizontal pendulum;" in two of which M. Zöllner de. scribes the instrument as he constructs and uses it, giving several observations made with it, which indicate its great sensitive. ness. In a third paper he represenis that the idea was first conceived by Lorenz Hengler, a writer in "Dingler's Polytechnisches Journal " in 832 ; while in a fourth note on the subject, Prof. Safarik produces evidence of the same fact, and also shows that the bold idea of demonstrating the variations of gravity and of cosmic attractions by terrestrial observations in one place, had already been expressed and experimented on by Gruithuisen, some fifty.two years before Zöllner, viz, in $181 \%,-M$. von Bezold communicates the first part of a valuable paper on the law of colour mixtures, and the physiological primary colours; and Prof. Clausius discusses a new mechanical proposition with reference to stationary motions. - In a note translated from the Italian, the question is considered by Prof. Roiti, Is the electric current an ether current? He argued that if this were the case, then the velocity of propagation of light in a body traversed by a galvanic current must be altered by the direction of this current. In his experiments he caused rays from two parallel slits to pass through two cell-divisions, respectively, of a rectangular glass vessel containing sulphate of zinc solution (the thickness of the dividing wall being equal to the interval between the slits). Interference fringes were obtained at the exit of the rays. Four electrodes being inserted, so that a current passed in opposite directions in the two cells, this had no effect in displacement of the fringes. M. Roiti concludes that if the galvanic current were an ether current, it must have a very small velocity, less than 200 metres per second, which does not agree with the phenomena of galvanic electricity.-Prof. Mach's paper on the stroboscopic determination of the pitch of tones, deserves the attention of musicians and others.

Der Naturforscher, Nov. 1873.--Among the botanical notes in this number is one on the age and mode of growth of woody plants in Greenland. M. IKraus finds that these plants often attain great age ( $x$ 50 years, e.g. in the case of some willows), but that the annual increase of thickness is extremely small, $\mathbf{I} \cdot 5 \mathrm{~mm}$. at the maximum. - Some experiments described by M. Godlewski prove that formation of starch in chlorophyll granules is not. possible without access of $\mathrm{CO}_{2}$; that the liberation of starch from these granules may occur in bright light; that we cannot, from absence of starch, infer there is no process of assimilation; and that the cause of change of form in etiolated plants does not 